\title{
Poor optical stability of molecular dyes when used as absorbers in water-based tissue-simulating phantoms
}

Blaž Cugmas, Peter Naglič, Sunil Paul Matthew Menachery, Franjo Pernuš, Boštjan Likar

Blaž Cugmas, Peter Naglič, Sunil Paul Matthew Menachery, Franjo Pernuš, Boštjan Likar, "Poor optical stability of molecular dyes when used as absorbers in water-based tissue-simulating phantoms," Proc. SPIE 10870, Design and Quality for Biomedical Technologies XII, 108700N (27 February 2019); doi: 10.1117/12.2506977

SPIE. Event: SPIE BiOS, 2019, San Francisco, California, United States 


\title{
Poor optical stability of molecular dyes when used as absorbers in water-based tissue-simulating phantoms
}

\author{
Blaž Cugmas*a,b, Peter Naglič ${ }^{\mathrm{b}}$, Sunil Paul Mathew Menachery ${ }^{\mathrm{c}}$, Franjo Pernušb ${ }^{\mathrm{b}}$, Boštjan Likar ${ }^{\mathrm{b}}$ \\ ${ }^{a}$ Biophotonics Laboratory, Institute of Atomic Physics and Spectroscopy, University of Latvia, \\ 19 Raina Blvd., LV-1586, Riga, Latvia, EU \\ ${ }^{b}$ Laboratory for Imaging Technologies, Faculty of Electrical Engineering, University of Ljubljana, \\ Tržaška 25, SI-1000 Ljubljana, Slovenia, EU \\ ${ }^{c}$ Division of Environmental Science and Engineering, Pohang University of Science and Technology \\ (POSTECH), Pohang, 37673, South Korea
}

\begin{abstract}
Biomedical optical systems and models can be easily validated by the use of tissue-simulating phantoms. They can consist of water-based turbid media which often include inks (India ink and molecular dyes) as absorbers. Optical stability of commonly exploited inks under the influence of light, $\mathrm{pH}$ changes and the addition of $\mathrm{TiO}_{2}$ and surfactant, was studied. We found that the exposure to ultraviolet and visible light can crucially affect the absorption properties of molecular dyes. On average, absorption peaks decreased by $47.3 \%$ in 150 exposure hours. Furthermore, dilution can affect ink's $\mathrm{pH}$ and by that, its decay rate under light exposure. When $\mathrm{TiO}_{2}$ was added to the phantoms, all molecular dyes decayed rapidly. Photocatalytic nature of $\mathrm{TiO}_{2}$ can be partially avoided by selecting $\mathrm{TiO}_{2}$ with surface and crystal structure modification. Surfactant, normally present in the phantoms with polystyrene spheres, can cause absorption peak shifts up to $20 \mathrm{~nm}$ and amplitude changes of $29.6 \%$. Therefore, it is crucial to test the optical stability of inks in the presented manner before their exploitation in water-based phantoms.
\end{abstract}

Keywords: tissue-simulating phantoms, turbid media, molecular dyes, optical spectroscopy, optical stability, India ink, surfactant

\section{INTRODUCTION}

Tissue-simulating phantoms are indispensable for the field of biomedical optics since they serve as a substitute for biological tissues by mimicking their optical ${ }^{1,2}$ and mechanical ${ }^{3}$ properties. They empower a quick, cheap and reliable validation of new light-propagation models and system designs in optical spectroscopy or imaging. In order to do so, the phantoms have to provide desired optical properties regarding absorption $\left(\mu_{a}\right)$ and scattering coefficients $\left(\mu_{s}\right)$. This can be achieved by adding desired amounts of absorbers and scatterers into phantom matrixes (e.g., water, gelatin, and silicone).

When it comes to the water-based turbid phantoms, polystyrene microspheres ${ }^{4,5}$ or $\mathrm{TiO}_{2}{ }^{6}$ are often employed as scatterers. On the other hand, absorption properties can be manipulated by exploiting various inks. Among these, India ink is common ${ }^{7}$ since it is chemically and optically stable ${ }^{8}$. However, India ink also scatters light and therefore, it cannot be treated as a pure absorber'. To overcome this limitation, molecular dyes are employed instead. Some studies reported using Methylene Blue ${ }^{10}$, Evans Blue ${ }^{5}$ and various blue, green and red fountain pen inks ${ }^{11-14}$.

The selection between India ink and molecular dyes is usually governed by the study purpose and environment. For example, if fluorescence should be avoided and chemical and spectroscopic stability is needed, India ink prevails. Additionally, it can be used for solid phantoms since diffusion through the gel or polymer matrix will not happen. However, the main disadvantage of India ink is the considerable scattering component. Thus, determining optical properties requires a measurement of the collimated transmittance, diffuse reflectance and diffuse transmittance. In contrast, molecular dyes require only a collimated transmittance measurement to determine their absorption coefficients.

*blaz.cugmas@1u.lv 
Even though the absorbers above are widely applied, their stability has been studied minimally. When it comes to the absorbers, Ninni et al. ${ }^{8}$ showed that the optical properties of India ink differ little between different batches and stay stable for several weeks. On the other hand, it was reported that printer inks could be affected by light, ozone, water, and heat ${ }^{15}$.

In this study, we present key findings on the optical stability of commonly exploited inks by simulating some of the typical situations in the preparation and employment of the tissue simulating water-based turbid phantoms in optical spectroscopy and imaging. Namely, popular molecular dyes and India ink were exposed to the influence of light, $\mathrm{pH}$ changes and to the addition of $\mathrm{TiO} 2$ and surfactant.

\section{MATERIAL AND METHODS}

During the study, the inks, listed in Table 1, were exposed to ultraviolet (UV) and visible light, to changes in $\mathrm{pH}$ values and to the addition of $\mathrm{TiO}_{2}$ and surfactant. It was shown that $\mathrm{TiO}_{2}$ is a potentially photocatalytic scatterer which can destroy organic molecules via oxidation ${ }^{16}$. On the other hand, a surfactant is normally employed in the suspensions of polystyrene sphere in order to avoid flocculation.

According to the ink manipulation, samples were arranged into four groups:

1. Inks from original packing diluted with deionized water. Table 1 lists inks' solution volume fractions $V F$. $V F$ is a multiplicative inverse of dilution factor $D F: V F=D F^{-1}$.

2. Inks from original packing diluted with a buffer, which corresponded to the original $\mathrm{pH}$ of the undiluted ink. Dilution factors (DFs) remained the same as in Group 1. pH values and buffer components are listed in Table 1.

3. Firstly, inks were prepared in the same manner as in Group 1 - they were diluted with deionized water. Additionally, $\mathrm{TiO}_{2}$ (Sigma Aldrich, product number: 14027) was added at the concentration of $3.1 \mathrm{mg} / 100 \mathrm{ml}$.

4. Firstly, inks were prepared in the same manner as in Group 1 - they were diluted with deionized water. Secondly, a nonionic surfactant (Sigma Aldrich, Tween ${ }^{20}$, product number: 1379) was added. According to the manufacturer's recommendation, the dilution factor (DF) of the added surfactant was 1000. Additionally, we increased the surfactant concentration ten times ( $D F$ was 100).

Table 1. Volume fraction VF (the multiplicative inverse of dilution factor DF) of the exploited inks, diluted with deionized water (Group 1) or corresponding buffer (Group 2). pH values of the original inks and buffers are also listed. Each corresponding buffer consisted of two main compounds provided in the annotations.

\begin{tabular}{llll}
\hline & Ink & $\mathrm{VF}$ & $\mathrm{pH}$ \\
\hline 1 & Eosin (SA 318906) & $7.9 \times 10^{-5}$ & $6.9^{\mathrm{a}, \mathrm{b}}$ \\
2 & Methylene Blue (SA 319112) & $5.4 \times 10^{-3}$ & $5.4^{\mathrm{b}, \mathrm{c}}$ \\
3 & India ink (DR 144028028) & $7.9 \times 10^{-5}$ & $8.0^{\mathrm{a}, \mathrm{c}}$ \\
4 & Royal Blue (P 4001) & $1.0 \times 10^{-3}$ & $2.8^{\mathrm{c}, \mathrm{d}}$ \\
5 & Brillant Red (P 4001) & $3.5 \times 10^{-4}$ & $8.2^{\mathrm{d}, \mathrm{e}}$ \\
6 & LiveLine Green (V) & $3.1 \times 10^{-4}$ & $6.1^{\mathrm{a}, \mathrm{b}}$ \\
7 & LiveLine Black (V) & $4.9 \times 10^{-4}$ & $3.4^{\mathrm{c}, \mathrm{d}}$
\end{tabular}

$\mathrm{SA}=$ Sigma Aldrich, USA, DR = Daler Rowney, United Kingdom, $\mathrm{P}=$ Pelikan, Germany, $\mathrm{V}=$ Vivapen, Slovenia. Buffer components: $\mathrm{a}=\mathrm{KH}_{2} \mathrm{PO}_{4}, \mathrm{~b}=\mathrm{NaOH}, \mathrm{c}=\mathrm{C}_{8} \mathrm{H}_{5} \mathrm{KO}_{4}, \mathrm{~d}=\mathrm{HCl}, \mathrm{e}=\mathrm{NH}_{2} \mathrm{C}\left(\mathrm{CH}_{2} \mathrm{OH}\right)_{3}$. 
Samples diluted with deionized water from Group 1 were used in the study of light exposure influence. Samples diluted with the corresponding buffer from Group 2 were used to study the $\mathrm{pH}$ effect on inks' optical stability. Samples from Group 3 were used to investigate the photocatalytic nature of $\mathrm{TiO}_{2}$. Finally, samples from Group 4 were studied for the influence of surfactant on ink optical properties.

After the ink preparation, each sample in Groups 1,2 and 3 was split into four cuvettes. Two cuvettes were kept in darkness during the whole study, representing control samples. The other two cuvettes were exposed to the UV and visible light. On the other hand, each sample in Group 4 was split into two cuvettes. Group 4 samples were not exposed to light since all samples were studied directly after the surfactant addition. All samples were kept in an air-conditioned room, so the temperature was stable during the whole 150 hours. However, sample temperature was not recorded.

Samples from Groups 1, 2 and 3 were exposed to UV (irradiance: $3.28 \mathrm{~W} / \mathrm{m} 2$ ) and visible light (irradiance: $10.87 \mathrm{~W} / \mathrm{m} 2$ ) provided by the fluorescent lamps (Actinic BL TL TL-D 18W/10 1SL/25 and Master TL-D 90 Graphica 18W/965 SLV/10, Philips, The Netherlands), mimicking the spectrum of solar radiation at the sea level. The transmittance measurements were performed immediately after the dilution (at time $\left.t_{0}\right)$ and after $2\left(t_{1}\right), 25\left(t_{2}\right), 50\left(t_{3}\right)$ and 150 hours $\left(t_{4}\right)$ of the UV and visible light exposure. In order to assure measurements with an adequate signal-to-noise ratio when using 1-cm optical path length PMMA cuvettes (Poly(methyl methacrylate) UV Makro, Ref. 2722110, Ratiolab, Germany), ink volume fractions were selected in a manner that the maximal absorption coefficient $\left(\mu_{a}\right)$ reached values of around 1.5 $\mathrm{cm}^{-1}$ (in Groups 1, 2 and 4). Samples with higher absorption coefficients of 10 and $100 \mathrm{~cm}^{-1}$ were obtained by taking into account the ink concentration needed for the absorption coefficient of $1 \mathrm{~cm}^{-1}$, which could be measured using the 1-cm optical path length cuvettes. Subsequently, by increasing the ink concentration for 10- and 100-times, higher absorption coefficients of 10 and $100 \mathrm{~cm}^{-1}$ were achieved. With samples in Group 3, the total attenuation coefficient was around 2.0 $\mathrm{cm}^{-1}$ due to the addition of $\mathrm{TiO}_{2}$. Since $\mathrm{TiO}_{2}$ was slowly sedimenting during the experiment, the samples had to be shaken to ensure a homogeneous distribution of $\mathrm{TiO}_{2}$.

The sample transmittance between 400 and $700 \mathrm{~nm}$ was acquired by a spectrometer (AvaSpec-2048-TEC-FT, 177 to $1098 \mathrm{~nm}$, Avantes, The Netherlands). A broadband halogen light source (AvaLight-Hal LS, Avantes) was employed. The irradiances of the fluorescent lamps were estimated by a spectroradiometer Jeti Specboc 1200 (Jeti Technische Instrumente, Germany). The sample $\mathrm{pH}$ was measured by a pH meter (HI98130, Hanna Instruments, USA). Since most of the samples were purely absorbing, the transmittance was converted to the absorbance $(A)$ and subsequently to the absorption coefficient $\mu_{a}$. For each measurement at time $t, t \in\left\{t_{0}-t_{4}\right\}$, we defined a so-called normalized absorption peak $\mu_{a, n o r m}(t)$ where a dominant absorption peak of each ink was normalized by its initial value, obtained at the beginning of the experiment $\left(t_{0}\right)$.

To estimate the evaporation of water from the cuvettes during the experiment, the mass of the samples at the beginning $\left(m_{0}\right)$ and the end of the experiment $\left(m_{4}\right)$ was measured. Since the average mass loss in 150 hours was $3.17 \%$, the absorption coefficient measurements were corrected, linearly with the elapsed time $(t)$ :

$$
\mu_{a, a d j u s t e d}(t)=\frac{\mu_{a}}{\left(1-\frac{m_{4}}{m_{0}}\right) \cdot \frac{t}{t_{4}}+1}
$$

\section{RESULTS AND DISCUSSION}

\subsection{Light exposure}

The timecourse of the normalized absorption peaks $\mu_{a, \text { norm }}$ of the samples in Group 1 is presented in Table 2 and Fig. 1(a). The results show that UV and visible light can crucially affect the absorption properties of inks, diluted by deionized water. Red inks (Inks 1 and 5) proved to be very sensitive to light. Merely in one day, both inks lost more than $80 \%$ of their absorption capability. At the end of the exposure, inks were completely decomposed (i.e., a normalized absorption peak was $0.4 \%$ and $0.3 \%$ for Ink 1 and 5, respectively). Figure 1(b) presents the timecourse of the absorption spectra of Ink 1. It is very likely that the energy of UV and visible light photons initiates various photochemical reactions which affect colored molecules or colorless ink additives ${ }^{17}$. This leads to compounds which are colorless or have 
different optical properties. On the other hand, Inks 3,6 and 7 remained optically stable during the whole experiment (Fig. 1(a)).

Moreover, we observed that diluting inks with deionized water alone can affect their optical properties through time. Most of the inks in the control group, which were not exposed to the light, exhibited a decrease in the normalized absorption peak for a few percentage points (up to $5.3 \mathrm{pp}$ ). However, Pelikan inks (Inks 4 and 5) exhibited even bigger sensitivity since the absorption peak decreased by up to $24.9 \%$.

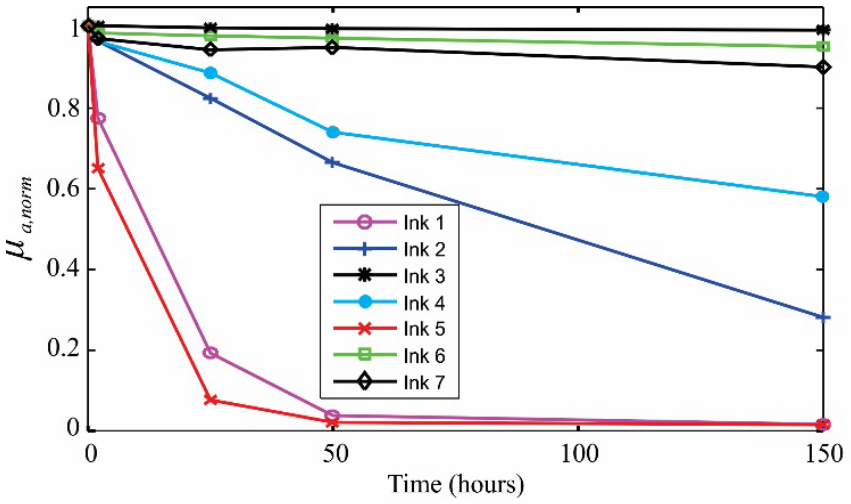

(a)

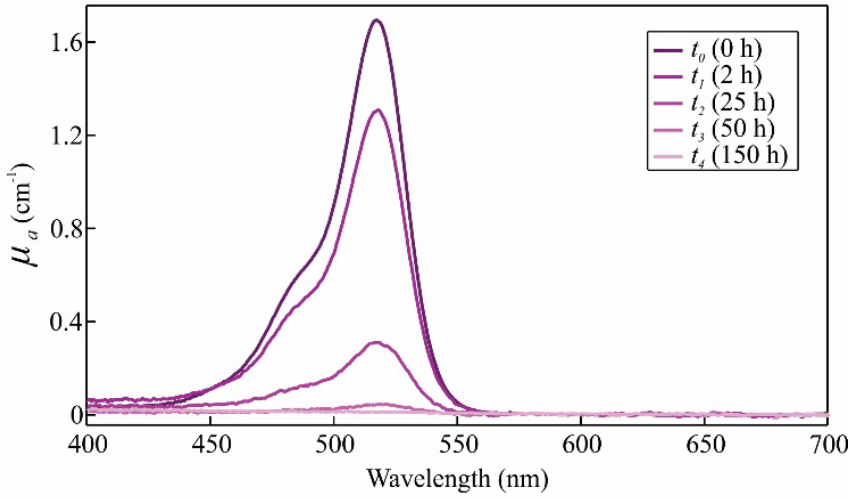

(b)

Figure 1. (a) The timecourse of the normalized absorption peaks $\left(\mu_{a, n o r m}\right)$ of inks in Group 1, exposed to the UV and visible light. (b) Absorption spectra of Ink 1, acquired at 0,2, 25, 50 and 150 hours after the light exposure.

Table 2. The timecourse of the normalized absorption peaks $\left(\mu_{a, n o r m}\right)$ of the deionized water diluted samples in Group 1. The normalized absorption peaks of control samples, which were not exposed to the UV and visible light, are listed in brackets.

\begin{tabular}{lcccc}
\hline Ink & $t_{l}(2 \mathrm{~h})$ & $t_{2}(25 \mathrm{~h})$ & $t_{3}(50 \mathrm{~h})$ & $t_{4}(150 \mathrm{~h})$ \\
\hline 1 & $77.0 \%(97.5 \%)$ & $18.2 \%(95.8 \%)$ & $2.6 \%(96.0 \%)$ & $0.4 \%(94.7 \%)$ \\
2 & $96.2 \%(98.4 \%)$ & $81.9 \%(97.6 \%)$ & $65.8 \%(95.4 \%)$ & $27.2 \%(95.4 \%)$ \\
3 & $100.0 \%(99.9 \%)$ & $99.5 \%(99.4 \%)$ & $99.3 \%(100.0 \%)$ & $98.9 \%(100.0 \%)$ \\
4 & $96.1 \%(98.4 \%)$ & $88.2 \%(94.2 \%)$ & $73.4 \%(82.7 \%)$ & $57.3 \%(75.1 \%)$ \\
5 & $64.4 \%(97.3 \%)$ & $6.5 \%(93.4 \%)$ & $0.9 \%(91.7 \%)$ & $0.3 \%(88.8 \%)$ \\
6 & $98.2 \%(98.8 \%)$ & $97.5 \%(97.8 \%)$ & $96.9 \%(99.0 \%)$ & $94.8 \%(98.1 \%)$ \\
7 & $96.8 \%(97.3 \%)$ & $94.0 \%(96.3 \%)$ & $94.6 \%(97.7 \%)$ & $89.7 \%(97.2 \%)$ \\
\hline
\end{tabular}

In this study, relatively low ink concentrations were used in order to assure measurements with an adequate signal-tonoise ratio. Nevertheless, the values of the absorption coefficient were around $1.5 \mathrm{~cm}^{-1}$ which are in line with the values, observed in human $\operatorname{skin}^{18}$. Since some studies showed that skin could also exhibit much higher absorption coefficients, i.e., up to $6 \mathrm{~cm}^{-1}$ in visible and $22 \mathrm{~cm}^{-1}$ in NIR wavelength range ${ }^{18}$, we additionally increased the ink concentrations for Inks 1 and 2. Samples with absorption coefficients of 1,10 and $100 \mathrm{~cm}^{-1}$ were prepared and exposed to the UV and visible light in the same manner as samples in Group 1.

The results proved that concentrated ink is more resistant to the destructive effects of light. When dilution factor DF was 100 times smaller, the decay rate of eosin (Ink 1) was much slower. The improvements in the normalized absorption peaks $\left(\mu_{a, n o r m}\right)$ of Ink 1, comparing to the data in Table 2, were 7.2 percentage points (pp), $13.9 \mathrm{pp}, 12.0 \mathrm{pp}$ and $3.4 \mathrm{pp}$ for measurements taken after $2\left(t_{1}\right), 25\left(t_{2}\right), 50\left(t_{3}\right)$ and 150 hours $\left(t_{4}\right)$, respectively. For example, the normalized absorption peak of highly concentrated ink was $14.6 \%$ after 50 hours (at the time $t_{3}$ ), what is almost the value of the absorption peak of the original ink dilution after one-day exposure (at the time $t_{2}$ ).

The similar phenomenon was noticed for Methylene Blue (Ink 2) which even proved to be optically stable during most of the experiment. First signs of the ink decay appeared after 150 exposure hours $\left(t_{4}\right)$. On the other hand, original ink dilution started decaying immediately after the first exposure to the light. The improvements in the normalized 
absorption peaks $\left(\mu_{a, n o r m}\right)$ of Ink 2 with 10 times lower dilution comparing to the data in Table 2 were $3.8 \mathrm{pp}, 10.3 \mathrm{pp}$, $21.9 \mathrm{pp}$ and $34.5 \mathrm{pp}$ for measurements taken after $2\left(t_{1}\right), 25\left(t_{2}\right), 50\left(t_{3}\right)$ and 150 hours $\left(t_{4}\right)$, respectively. When Ink 2 had 100 times lower dilution, the improvements in the normalized absorption peaks $\left(\mu_{a, \text { norm }}\right)$ were $3.8 \mathrm{pp}, 18.1 \mathrm{pp}, 34.2 \mathrm{pp}$ and $67.6 \mathrm{pp}$ for measurements taken after $2\left(t_{1}\right), 25\left(t_{2}\right), 50\left(t_{3}\right)$ and 150 hours $\left(t_{4}\right)$, respectively.

The reason for higher optical stability is because higher ink concentrations attenuate the light and thus reduce the density of photons that reach ink molecules in the center of a cuvette. This way, ink decays much slower in the sample center than on the sample surface. The phenomenon above of slower decay of highly concentrated inks can also be related to $\mathrm{pH}$ changes which were less significant in the case of lower ink dilutions (i.e., higher ink volume fraction). The contribution of $\mathrm{pH}$ change will be discussed in the following section.

\section{$3.2 \mathrm{pH}$ changes}

$\mathrm{pH}$ can affect the structure and therefore, also the optical properties of many organic molecules, including molecular dyes ${ }^{19}$. Since dilution with water can change sample $\mathrm{pH}$ value ${ }^{20}$, we expected that inks, diluted with the corresponding buffers (Group 2), would exhibit better stability in the pH-preserved environment. However, in comparison with Group 1 (Table 2), preserving original ink's $\mathrm{pH}$ does not generally guarantee a beneficial effect on the ink optical stability (Table 3). For selected inks, Fig. 2 shows the differences in the timecourse of the normalized absorption peaks when inks were diluted with deionized water (Group 1) or pH-preserving buffer (Group 2). For Inks 2, 6 and 7, the decay rate under UV and visible light exposure was slower if the dilution was done with deionized water. On the other hand, Ink 4 exhibited better stability (up to 35.7 percentage points) when diluted with the corresponding buffer. For other inks, no significant change in the decay rate was noticed.

Table 3. The timecourse of the normalized absorption peaks $\left(\mu_{a, n o r m}\right)$ of the buffer diluted samples in Group 2. The normalized absorption peaks of control samples, which were not exposed to the UV and visible light, are listed in brackets.

\begin{tabular}{lcccc}
\hline Ink & $t_{l}(2 \mathrm{~h})$ & $t_{2}(25 \mathrm{~h})$ & $t_{3}(50 \mathrm{~h})$ & $t_{4}(150 \mathrm{~h})$ \\
\hline 1 & $73.4 \%(96.6 \%)$ & $14.1 \%(95.3 \%)$ & $1.9 \%(94.5 \%)$ & $0.0 \%(94.2 \%)$ \\
2 & $92.2 \%(99.0 \%)$ & $59.0 \%(96.8 \%)$ & $25.4 \%(97.4 \%)$ & $0.0 \%(94.8 \%)$ \\
3 & $99.4 \%(99.1 \%)$ & $97.4 \%(93.4 \%)$ & $96.1 \%(100.0 \%)$ & $96.8 \%(99.4 \%)$ \\
4 & $99.6 \%(100.0 \%)$ & $98.4 \%(98.8 \%)$ & $99.2 \%(98.9 \%)$ & $93.0 \%(97.7 \%)$ \\
5 & $61.0 \%(92.5 \%)$ & $7.2 \%(92.9 \%)$ & $0.6 \%(89.3 \%)$ & $0.0 \%(88.0 \%)$ \\
6 & $98.0 \%(97.6 \%)$ & $95.5 \%(96.3 \%)$ & $94.4 \%(97.3 \%)$ & $78.3 \%(96.1 \%)$ \\
7 & $96.8 \%(100.0 \%)$ & $87.1 \%(98.1 \%)$ & $81.5 \%(96.4 \%)$ & $70.9 \%(93.5 \%)$ \\
\hline
\end{tabular}

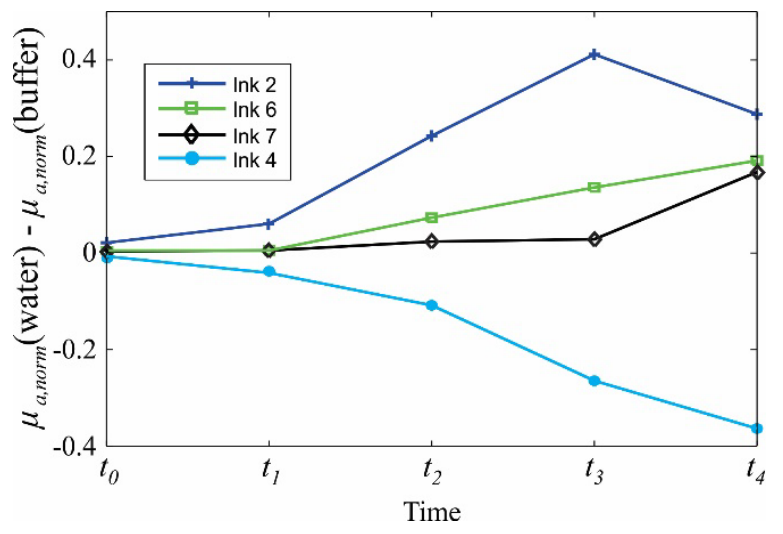

Figure 2. The timecourse of the difference between the normalized absorption peaks $\left(\mu_{a, \text { norm }}\right)$ of Inks $2,4,6$ and 7 , diluted with deionized water or buffer. 
In the previous Section ("Light exposure"), we have observed that the control samples which were not exposed to light, still exhibited some decrease in the normalized absorption peaks. This is especially true for Inks 4 and 5 . It seems that in the case of Ink 4, the stability was significantly improved when the ink was diluted with a buffer. The normalized absorption peak showed almost no decline within the 150 exposure hours, while the normalized absorption peak dropped by $24.9 \%$ when the ink was diluted by deionized water. As shown in Table 1 , Ink 4 is very acidic $(\mathrm{pH}=2.8)$ and diluting the sample with deionized water increases its $\mathrm{pH}$ above 5.4, what can cause ink degradation.

Comparing samples from Groups 1 and 2 has revealed another fact - some inks are composed of two dye types which are differently sensitive to light (Fig. 3). For example, when Ink 2 was diluted with deionized water and exposed to light, absorbance decreased evenly across the whole spectrum (Fig. 3(a)). However, when the samples were diluted in the corresponding buffer, a dye which mostly absorbs red light, decayed much faster what resulted in a shift of the dominant absorption peak (Fig. 3(b)).

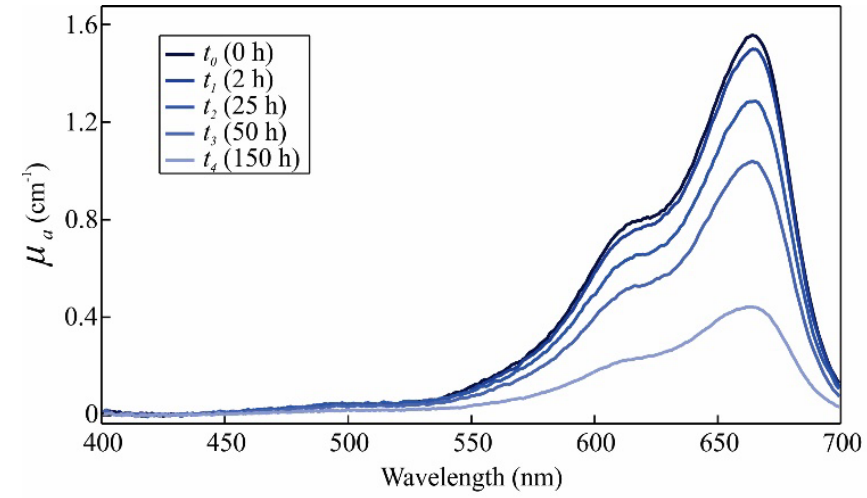

(a)

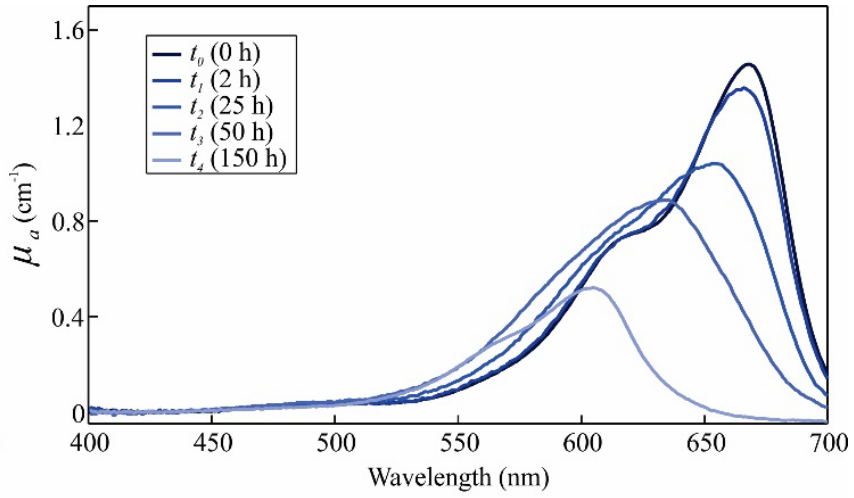

(b)

Figure 3. Absorption spectra of Ink 2, diluted in (a) deionized water and (b) corresponding buffer, acquired at 0, 2, 25, 50 and 150 hours after the light exposure.

The nature of diluent (water or buffer) can affect the $\mathrm{pH}$ and thereby many physical and chemical properties of inks. For example, the initial $\mathrm{pH}$ of Methylene Blue (Ink 2) solutions prepared in deionized water, was shifted to 7.1. The samples prepared in a suitable buffer solution, however, retained the original $\mathrm{pH}$ of 5.4. It is expected that ionized structure of the cationic dyes like Methylene Blue observed in acidic $\mathrm{pH}$ becomes neutral upon $\mathrm{pH}$ increment. It is, thus, expected that the samples diluted in deionized water might contain more cationic molecules than the ones prepared in the buffer.

On the other hand, anionic dyes like brilliant red (Ink 5) tend to be ionized in higher alkaline $\mathrm{pH}$. Hence, the $\mathrm{pH}$ difference of samples diluted in deionized water $(\mathrm{pH}=5.9)$ and corresponding buffer $(\mathrm{pH}=8.3)$ likely results in the existence of neutral and ionized dye molecules in samples diluted in water and buffer, respectively. Although a detailed investigation on the chemical nature of various inks concerning $\mathrm{pH}$, is beyond the scope of this study, it is highly possible that the stability of neutral/ionic structures of various ink molecules towards light irradiation might be different. Hence, the significantly different ink degradation in the case of samples prepared in deionized water or corresponding buffer solutions is highly anticipated.

\section{3 $\mathrm{TiO}_{2}$ effects}

The timecourse of the normalized absorption peaks of the samples in Group 3 is presented in Table 4. We can see that introducing $\mathrm{TiO}_{2}$ to the phantoms and subsequently exposing them to UV and visible light, is highly destructive to inks. While India ink exhibited limited changes, the absorption peaks of molecular dyes decreased significantly. On average, the absorption peak decreased by $38.7 \%$ after only two hours $\left(t_{l}\right)$ of light exposure $\left(28.3 \mathrm{Wh} / \mathrm{m}^{2}\right)$. At the end of the experiment $\left(t_{4}\right)$, the absorption peaks were lower for $83.4 \%$, meaning that the molecular dyes decayed completely. Furthermore, the absorption peaks of the samples, kept in darkness (control group), decreased on average by $11.1 \%$, which is slightly more than the decrease in control samples of Groups 1 and 2 ( $7.2 \%$ and 5.2\%, respectively). We assume that the phenomenon partially occurred because the samples were exposed to the halogen lamp light during the transmission acquisition. Another explanation for the phenomenon can be found in the adsorption of dye the molecules 
on $\mathrm{TiO}_{2}$ surface ${ }^{21}$ what leads to lower concentration of ink in the solution. To exclude the influence of agglomeration, we exposed a suspension of $\mathrm{TiO}_{2}$ without inks to UV and visible light. After 150 hours, no change in transmittance was noticed.

Table 4. The timecourse of the normalized absorption peaks $\left(\mu_{a, n o r m}\right)$ of the deionized water diluted samples with $\mathrm{TiO}_{2}$ in $\mathrm{Group}_{3}$. The normalized absorption peaks of control samples, which were not exposed to the UV and visible light, are listed in brackets. An anomalous measurement (i.e., outlier) is marked with *.

\begin{tabular}{lcccc}
\hline Ink & $t_{1}(2 \mathrm{~h})$ & $t_{2}(25 \mathrm{~h})$ & $t_{3}(50 \mathrm{~h})$ & $t_{4}(150 \mathrm{~h})$ \\
\hline 1 & $33.9 \%(90.4 \%)$ & $10.2 \%(81.6 \%)$ & $10.5 \%(81.0 \%)$ & $10.2 \%(77.8 \%)$ \\
2 & $12.2 \%(93.5 \%)$ & $1.9 \%(78.8 \%)$ & $0.7 \%(80.9 \%)$ & $0.0 \%(78.6 \%)$ \\
3 & $92.2 \%(94.8 \%)$ & $92.2 \%(94.7 \%)$ & $98.6 \%(106.3 \% *)$ & $88.2 \%(94.6 \%)$ \\
4 & $88.1 \%(99.1 \%)$ & $26.0 \%(96.9 \%)$ & $5.9 \%(98.5 \%)$ & $0.5 \%(99.5 \%)$ \\
5 & $62.0 \%(96.6 \%)$ & $19.3 \%(92.1 \%)$ & $16.4 \%(90.8 \%)$ & $14.2 \%(87.8 \%)$ \\
6 & $66.0 \%(98.0 \%)$ & $6.7 \%(93.0 \%)$ & $3.7 \%(93.3 \%)$ & $1.5 \%(89.4 \%)$ \\
7 & $74.4 \%(97.2 \%)$ & $11.5 \%(96.8 \%)$ & $6.6 \%(96.6 \%)$ & $1.3 \%(94.4 \%)$ \\
\hline
\end{tabular}

It is somehow evident that the $\mathrm{TiO}_{2}$ concentration affects the ink's decay rate. In an additional test, we prepared samples from Inks 1 and 6 with original $(3.1 \mathrm{mg} / 100 \mathrm{ml})$ and 10 times smaller $\mathrm{TiO}_{2}$ concentrations $(0.3 \mathrm{mg} / 100 \mathrm{ml})$. By lowering the $\mathrm{TiO}_{2}$ concentration, the ink decay rate decreased as well. After 2 hours $\left(t_{1}\right)$, the normalized absorption peak of Ink 1 was $33.9 \%$ (Table 4). However, when the $\mathrm{TiO}_{2}$ concentration was lower, the normalized absorption peak only decreased to $60.8 \%$. The slower decay rate was even more evident in Ink 6 . After 2, 25, 50 and 150 hours, the normalized absorption peaks were $93.3 \%$ (originally: $66.0 \%), 52.9 \%(6.7 \%), 31.9 \%(3.7 \%)$ and $3.4 \%(1.5 \%)$, respectively.

Photocatalytic nature of $\mathrm{TiO}_{2}$ can be partially avoided by selecting $\mathrm{TiO}_{2}$ with surface and crystal structure modifications. We have additionally introduced $\mathrm{TiO}_{2}$ nanoparticles (CCR $220 \mathrm{Mn}$, particle size: $30 \mathrm{~nm}$, surface modification: $\mathrm{Al}_{2} \mathrm{O}_{3}$, crystal structure modification: Mn ions, Cinkarna, Celje, Slovenia) to the solutions of Inks 1 and 6 in Group 3. According to internal studies on scattering properties, modified $\mathrm{TiO}_{2}$ consisted out of much smaller particles than $\mathrm{TiO}_{2}$ powder used before. Optically, this resulted in scattering, which is stronger dependent on the wavelength (e.g., Rayleigh scattering).

This resulted in an evident increase in their optical stability (Fig. 4). For example, after 25 hours $\left(t_{2}\right)$, the absorption peak of Ink 6 decreased by $93.3 \%$ when the ink was used in conjunction with the original $\mathrm{TiO}_{2}$, while it only decreased by $18.4 \%$ when used in conjunction with the modified $\mathrm{TiO}_{2}$. What is more, when exploiting $\mathrm{TiO}_{2}$ nanoparticles, there were also fewer problems with particle sedimentation. On the other hand, an agglomeration of nanoparticles happened in some cases.

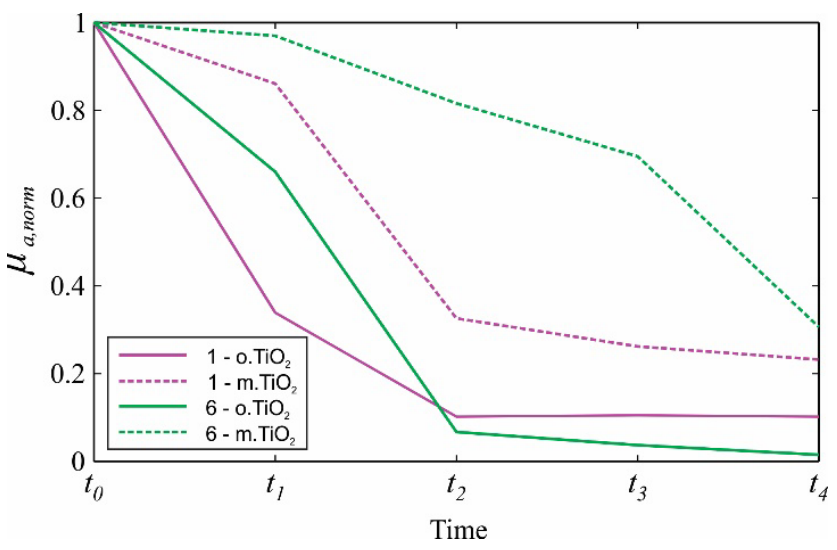

Figure 4. The timecourse of the normalized absorption peaks $\left(\mu_{a, n o r m}\right)$ of Inks 1 and 6 , presented with the original samples in Group 3 ("o. $\mathrm{TiO}_{2}$ ") and with an addition of the modified $\mathrm{TiO}_{2}$ ("m. $\mathrm{TiO}_{2}$ "). 


\subsection{Surfactant effects}

A surfactant is often added to the phantoms with polystyrene spheres to prevent flocculation. According to the manufacturer's recommendations, we added $0.1 \%$ of the surfactant to the samples in Group 4. Additionally, we increased surfactant volume fraction to $1.0 \%$. Results show that a surfactant can affect inks by changing their absorption peak wavelength (Fig. 5(a)) and absorption peak amplitude (Fig. 5(b)). Mean absorption peak shift was $9.1 \mathrm{~nm}$ and $10.5 \mathrm{~nm}$ when the surfactant volume fraction was $0.1 \%$ and $1.0 \%$, respectively. Inks 1 and 5 were especially sensitive since adding surfactant resulted in absorption peak shift of around $20 \mathrm{~nm}$ (Fig. 6(a)). On the other hand, the surfactant substantially affected absorption peak amplitude of inks 1 and 4 (up to 29.6\%, Fig. 6(b)). In our study, we have used a nonionic surfactant which can initiate binding interactions with anionic dye molecules (e.g., Inks 1 and 5) what leads to absorption peak shifts and amplitude changes ${ }^{22}$. In contrast, nonionic surfactants do not have an impact on cationic dyes $^{23}$, what was also proved for Methylene Blue (Ink 2).

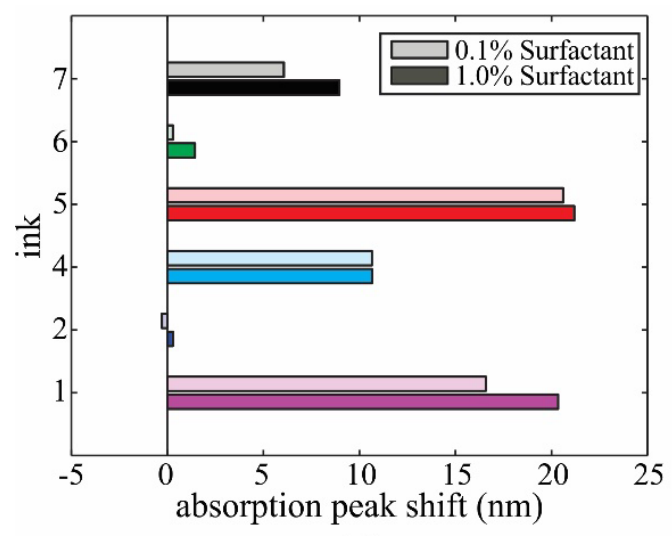

(a)

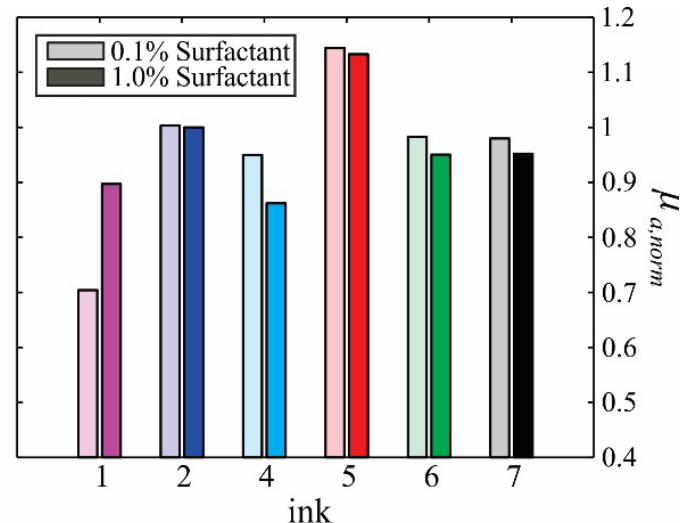

(b)

Figure 5. Surfactant effects. (a) Absorption peak shift (in $\mathrm{nm}$ ) and (b) absorption peak amplitude change when the surfactant is added (volume fraction: $0.1 \%$ and $1.0 \%$ ). India ink is omitted since it does not have an evident absorption peak.

In order to rule out refractive index changes due to the added surfactant, we measured the difference in transmittance between deionized water and a sample that in addition to the deionized water also contained $1 \%$ surfactant. We observed no significant differences in transmittance between the two cases, which would suggest that the refractive index mismatch in the cuvette is the same in both cases.

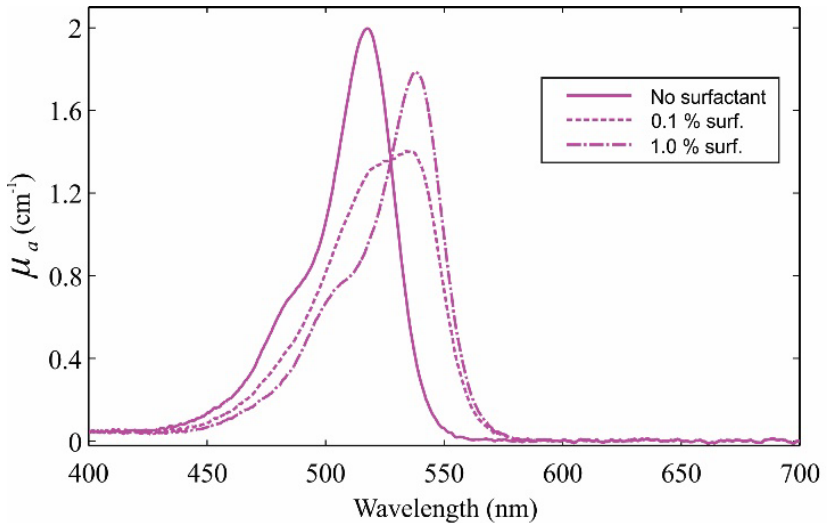

(a)

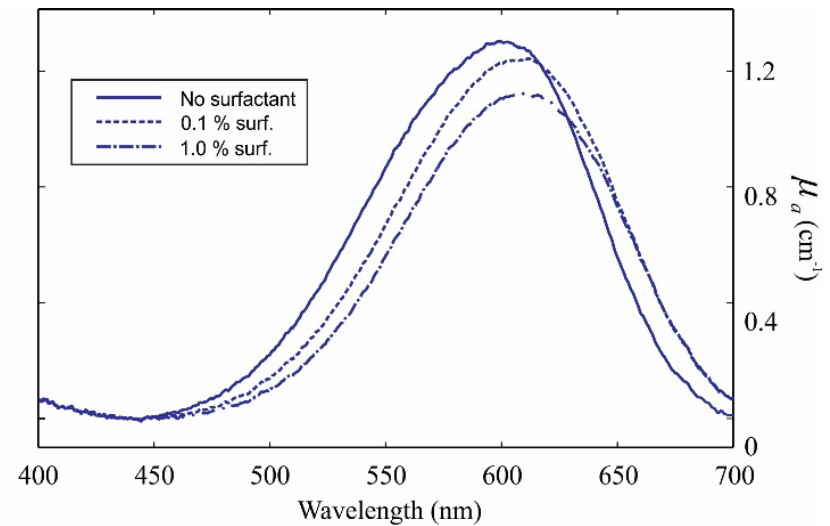

(b)

Figure 6. Surfactant effects on the absorption coefficient of (a) Ink 1 (Eosin) and (b) Ink 4 (Pelikan Blue) using two different surfactant volume fractions: $0.1 \%$ and $1.0 \%$. The original ink dilution absorption spectrum is given by solid line. 


\section{CONCLUSION}

In conclusion, inks (India ink and molecular dyes) can be affected by many factors such as light, $\mathrm{pH}, \mathrm{TiO}_{2}$, and surfactant. India ink (Ink 3) exhibited the highest optical stability what is in agreement with the study of Ninni et al. ${ }^{8}$. Molecular dyes performed worse; however, green ink (Ink 6) still achieved satisfactory results. The light exposure and the surfactant did not have any impact on the green ink, and the changes due to the exposure to $\mathrm{pH}$ and $\mathrm{TiO}_{2}$ were moderate. On the other hand, especially red inks (Inks 1 and 5) were optically very unstable since their optical properties changed significantly when exposed to light, $\mathrm{TiO}_{2}$, and the surfactant. Finally, this study showed that it is crucial to test the ink's stability before its exploitation in the water-based phantoms.

\section{FUNDING AND ACKNOWLEDGMENT}

The study was funded by the Slovenian Research Agency (ARRS) (P2-0232, L2-5472, J2-5473, J7-6781, J2-7211, J27118) and the Marie Skłodowska-Curie actions of the European Union (IF, DogSPEC, 745396).

We thank prof. dr. Grega Bizjak from the Laboratory of lighting and photometry, University of Ljubljana, for the use of their equipment.

\section{REFERENCES}

[1] Pogue, B. W. and Patterson, M. S., "Review of tissue simulating phantoms for optical spectroscopy, imaging and dosimetry," J. Biomed. Opt. 11(4), 041102 (2006).

[2] Rowe, P. I., Künnemeyer, R., McGlone, A., Talele, S., Martinsen, P. and Oliver, R., "Thermal Stability of Intralipid Optical Phantoms,” Appl. Spectrosc. 67(8), 993-996 (2013).

[3] Bregar, M., Cugmas, B., Naglič, P., Hartmann, D., Pernuš, F., Likar, B. and Bürmen, M., "Properties of contact pressure induced by manually operated fiber-optic probes," J. Biomed. Opt. 20(12), 127002 (2015).

[4] Vishwanath, K., Chang, K., Klein, D., Deng, Y. F., Chang, V., Phelps, J. E. and Ramanujam, N., "Portable, Fiber-Based, Diffuse Reflection Spectroscopy (DRS) Systems for Estimating Tissue Optical Properties," Appl. Spectrosc. 65(2), 206-215 (2011).

[5] Gamm, U. A., Kanick, S. C., Sterenborg, H. J. C. M., Robinson, D. J. and Amelink, A., "Quantification of the reduced scattering coefficient and phase-function-dependent parameter $\gamma$ of turbid media using multidiameter single fiber reflectance spectroscopy: experimental validation," Opt. Lett. 37(11), 1838-1840 (2012).

[6] Akarçay, H. G., Preisser, S., Frenz, M. and Rička, J., "Determining the optical properties of a gelatin TiO2 phantom at $780 \mathrm{~nm}$," Biomed. Opt. Express 3(3), 418-434 (2012).

[7] Spinelli, L., Botwicz, M., Zolek, N., Kacprzak, M., Milej, D., Sawosz, P., Liebert, A., Weigel, U., Durduran, T., Foschum, F., Kienle, A., Baribeau, F., Leclair, S., Bouchard, J.-P., Noiseux, I., Gallant, P., Mermut, O., Farina, A., Pifferi, A., et al., "Determination of reference values for optical properties of liquid phantoms based on Intralipid and India ink," Biomed. Opt. Express 5(7), 2037-2053 (2014).

[8] Ninni, P. D., Martelli, F. and Zaccanti, G., "The use of India ink in tissue-simulating phantoms," Opt. Express 18(26), 26854-26865 (2010).

[9] Madsen, S. J., Patterson, M. S. and Wilson, B. C., "The use of India ink as an optical absorber in tissuesimulating phantoms," Phys. Med. Biol. 37(4), 985 (1992).

[10] Aernouts, B., Van Beers, R., Watté, R., Lammertyn, J. and Saeys, W., "Dependent scattering in Intralipid ${ }^{\circledR}$ phantoms in the 600-1850 nm range," Opt. Express 22(5), 6086-6098 (2014).

[11] Naglič, P., Pernuš, F., Likar, B. and Bürmen, M., "Estimation of optical properties by spatially resolved reflectance spectroscopy in the subdiffusive regime," J. Biomed. Opt. 21(9), 095003 (2016).

[12] Nichols, B. S., Rajaram, N. and Tunnell, J. W., "Performance of a lookup table-based approach for measuring tissue optical properties with diffuse optical spectroscopy," J. Biomed. Opt. 17(5) (2012). 
[13] Reif, R., A’Amar, O. and Bigio, I. J., "Analytical model of light reflectance for extraction of the optical properties in small volumes of turbid media," Appl. Opt. 46(29), 7317-7328 (2007).

[14] de Bruin, D. M., Bremmer, R. H., Kodach, V. M., de Kinkelder, R., van Marle, J., van Leeuwen, T. G. and Faber, D. J., "Optical phantoms of varying geometry based on thin building blocks with controlled optical properties," J. Biomed. Opt. 15(2), 025001-025001-025010 (2010).

[15] E Dobric and I Bolanca Mirkovic and Z Bolanca., "Durability of ink jet prints," J. Phys. Conf. Ser. 231(1), 012009 (2010).

[16] Gligorovski, S., Strekowski, R., Barbati, S. and Vione, D., "Environmental Implications of Hydroxyl Radicals $(\bullet O H), "$ Chem. Rev. 115(24), 13051-13092 (2015).

[17] van Beek, H. C. A., "Light-induced colour changes in dyes and materials," Color Res. Appl. 8(3), 176-181 (1983).

[18] Bashkatov, A. N., Genina, E. A., Kochubey, V. I. and Tuchin, V. V., "Optical properties of human skin, subcutaneous and mucous tissues in the wavelength range from 400 to 2000 nm," J. Phys. -Appl. Phys. 38(15), 2543-2555 (2005).

[19] Slyusareva, E. A. and Gerasimova, M. A., "pH-Dependence of the Absorption and Fluorescent Properties of Fluorone Dyes in Aqueous Solutions," Russ. Phys. J. 56(12), 1370-1377 (2014).

[20] Bates, R. G., "Measurement of Effect of Dilution upon pH," Anal. Chem. 26(5), 871-874 (1954).

[21] Anselmi, C., Mosconi, E., Pastore, M., Ronca, E. and De Angelis, F., "Adsorption of organic dyes on TiO2 surfaces in dye-sensitized solar cells: interplay of theory and experiment," Phys. Chem. Chem. Phys. 14(46), 15963-15974 (2012).

[22] Kartal, Ç. and Akbaş, H., "Study on the interaction of anionic dye-nonionic surfactants in a mixture of anionic and nonionic surfactants by absorption spectroscopy," Dyes Pigments 65(3), 191-195 (2005).

[23] Sarkar, M. and Poddar, S., "Studies on the Interaction of Surfactants with Cationic Dye by Absorption Spectroscopy," J. Colloid Interface Sci. 221(2), 181-185 (2000). 